\title{
OS DESAFIOS DA PRODUÇÃO AGROECOLÓGICA E DA CONSTRUÇÃO DE UMA ESTRATÉGIA DE MERCADO DE CIRCUITO CURTO ATRAVÉS DA ENTREGA DOMICILIAR DE PRODUTOS
}

\author{
Tatiana Aparecida Balem ${ }^{1}$ \\ Ethyene de Oliveira Alves ${ }^{2}$ \\ Guilherme dos Santos Schmeling ${ }^{3}$
}

\begin{abstract}
RESUMO
Atualmente a busca por uma alimentação saudável tem deixado de ser um ato cogitativo para se tornar uma prática. Neste sentido, o objetivo deste trabalho é abordar as percepções dos consumidores e de uma família agricultora em transição agroecológica, que utiliza a entrega de cestas domiciliares como alternativa do mercado de circuito curto. A pesquisa realizou-se a partir de uma visita a propriedade e entrevista com a família produtora, a onze consumidores e a um extensionista rural. Através da pesquisa foi possível considerar que: a entrega domiciliar atinge um grupo de consumidores reflexivos; a relação neste mercado é fortalecida pela confiança e troca de saberes; esse modelo de mercado possui potencial expansivo, pois há demanda crescente de alimentos orgânicos e consumidores que preferem a entrega domiciliar. Contudo, ainda há espaço de aprendizado nessa relação de produção e consumo, pois a experiência mostra que há desafios a serem superados, tais como: organização do mercado de circuito curto, assistência técnica e aprendizados necessários tanto para os agricultores quanto para os consumidores.
\end{abstract}

Palavras-chave: alternativas de mercado, cestas orgânicas, consumidores conscientes, produção orgânica.

\section{THE CHALLENGES OF AGROECOLOGICAL PRODUCTION AND THE CONSTRUCTION OF A SHORT-CIRCUIT MARKET STRATEGY THROUGH AT DOMICILIARY DELIVERY OF PRODUCTS}

\begin{abstract}
Nowadays the search for a healthy diet has ceased to be a cogitative act to become a practice. In this sense, the objective of this work is to address the perceptions of the consumers and of an agricultural family in agroecological transition, which uses the delivery of home baskets as short circuit market alternative. The research was made through the property visit and interview with the producer family, eleven consumers and a rural extension worker. Through of research it was possible to consider: the home delivery reaches a group of reflective consumers; the relationship between

${ }^{1}$ Graduada em Agronomia (UFSM). Mestrado em Extensão Rural (UFSM). Doutorado em Extensão Rural (UFSM). Professora do Instituto Federal Farroupilha campus Júlio de Castilhos. E-mail: tatianabalem@yahoo.com.br

${ }^{2}$ Graduada em Curso Superior de Tecnologia em Produção de Grãos (IFFAR). E-mail: ethyoalves@gmail.com

3 Graduado em Curso Superior de Tecnologia em Produção de Grãos (IFFAR). E-mail: guilhermeschmeling@outlook.com
\end{abstract}


farmer and consumers in this market is strengthened by the trust and exchange of knowledge; this is a market with potential for expansion, there is a growing demand for organic food and consumers who prefer home delivery. However, there is still room for learning in this relation of production and consumption, since experience shows that there are challenges to be overcome, such as: organization of the short circuit market, technical assistance and learning necessary for both farmers and consumers.

Key words: conscious consumers; market alternatives, organic basket, organic production.

\section{INTRODUÇÃO}

Segundo Bianchini e Medaets (2013), o final da Segunda Guerra Mundial e o advento da Era Nuclear fizeram com que os temas ambientais e sociais, se internacionalizassem a partir de uma reflexão da sociedade sobre a depredação desmedida da natureza pelos avanços da agricultura, da indústria e do consumo crescente de alguns recursos naturais não renováveis. Além de demonstrar maior preocupação com o meio ambiente, a população mundial também passou a buscar por alimentos mais saudáveis com a ausência de produtos químicos, dando espaço para a produção agroecológica, sistema que além de envolver a produção sustentável respeitando os ecossistemas, também tem maior ênfase na saúde do consumidor (BIANCHINI e MEDAETS, 2013).

Autores afirmam que o regime alimentar construído pelo processo homogeneizante e aniquilador de culturas alimentares operados pela modernização da agricultura e pela indústria alimentícia, vem sendo questionado por uma nova consciência de alimentação (FRIEDMANN, 1993; GOODMAN, 2003; MCMICHEL, 2009; WISKERKE, 2009; MORGAN, 2010). Essa nova consciência de alimentação, reconstrução dos sistemas de produção, construção de formas de mercado mais justos e sustentáveis e principalmente pela busca de estratégias de relocalização do regime agroalimentar, vem sendo chamada de Narrativa Alternativa dos Alimentos (BALEM, 2015) ou de Redes Alternativas de Produção de Alimentos (GOODMAN, 2003) ou ainda, de Nova Equação Alimentar (MORGAN; SONINO, 2010). A Narrativa Alternativa dos Alimentos propõe um sistema agroalimentar que se opõem às características do sistema industrial de alimentos, tais como: homogeneização de produtos; diminuição da diversidade de alimentos consumidos; comida global, ou seja, eliminação da sazonalidade e do consumo de produtos locais; alimentos altamente processados e artificializados; contaminação química dos produtos (agrotóxicos e aditivos alimentares para conferir cor, sabor, forma e alta vida de prateleira).

De acordo com os pressupostos da construção da Narrativa Alternativa dos Alimentos o contraponto seria: a valorização e fortalecimento da agricultura de pequena escala; o desenvolvimento de sistemas produtivos sustentáveis orgânicos e/ou agroecológicos; a construção social de mercados locais; o fomento do apoio a produção local com fornecimento adequado de serviços, conhecimento, crédito, insumos e equipamentos adequados; mercados locais e regionais híbridos, para aquelas regiões onde a agricultura de pequena escala não consegue atender a demanda, assim agricultores de outras regiões se inseririam; a conscientização de novas gerações de consumidores, mais conscientes e mais demandantes dos produtos desse modelo de agricultura.

Identificamos empiricamente em Santa Maria-RS, agricultores orgânicos e agroecológicos que comercializam em mercados de circuitos curtos e utilizam mais de uma estratégia de comercialização. No entanto, para este trabalho, vamos explorar 
uma estratégia de comercialização desenvolvida por uma família composta por agricultores familiares. O presente trabalho tem por objetivo estudar as percepções dos consumidores e a construção da família agricultora em torno da estratégia de mercado de circuito curto de produtos orgânicos, através da entrega de cestas a domicílio. A entrega de cestas de produtos é uma forma de comercialização relativamente nova na cidade de Santa Maria, mas derivada de uma das mais antigas formas de comercialização da agricultura familiar, o ato de "quitandar". Os agricultores chamados de quitandeiros, antes do processo de modernização da agricultura, contavam com uma produção diversificada de alimentos para subsistências, com a comercialização dos excedentes de porta em porta ou em pequenos estabelecimentos comerciais urbanos.

Abordamos basicamente, uma caracterização da produção orgânica e do envolvimento da família nesse procedimento, assim como os elementos constituintes do processo de consumo via cestas de produtos entregues aos consumidores pelos agricultores.

\section{CARACTERIZAÇÃO DO ESTUDO}

A presente pesquisa é de caráter qualitativo e foi realizada através da aplicação de entrevistas, as quais foram direcionadas a uma família produtora de alimentos orgânicos e a um grupo de consumidores dos produtos produzidos por essa família, ambos residentes na cidade de Santa Maria-RS. Foram entrevistados onze consumidores, a família produtora e também um extensionista do Escritório Municipal da Emater-RS que acompanha o processo. A propriedade da família situa-se na comunidade de Três Barras, no município de Santa Maria, o qual possui uma população de 261.031 habitantes e 1.781 .757 quilômetros quadrados de área (IBGE, 2019), distribuídos no Centro Geográfico do Rio Grande do Sul. A propriedade localiza-se numa área de transição morfológica denominada Rebordo do Planalto, entre dois conjuntos fisiográficos, os quais estão representados pelo Planalto Meridional Brasileiro e a Depressão Central do Rio Grande do Sul.

Santa Maria é considerada o principal polo da região central do estado, pois não há nenhuma outra cidade com proporções semelhantes. Suas características funcionais urbanas repousam no setor terciário e ultrapassam os limites regionais, principalmente nas atividades ligadas ao setor comercial, educacional e serviços públicos, sediando instituições como a Universidade Federal de Santa Maria, Hospital Universitário e a Área de Segurança Nacional, formada pela Base Aérea e várias unidades do exército. Nesse sentido, é uma cidade que se configura em um importante polo consumidor.

Hoje em Santa Maria há uma emergência de grupos de consumidores de produtos orgânicos, sendo que no levantamento exploratório desse estudo identificamos quatro grupos, organizados em torno de agricultores que produzem de forma orgânica ou agroecológica. É importante perceber que esse movimento de aglutinação de um grupo de consumidores em volta de um agricultor, demonstra um processo diferenciado de mercado de circuito curto. No entanto, para esse estudo, optamos pela imersão em um grupo de produção e consumo.

O processo de análise dos dados foi realizado de acordo com as premissas de um estudo explicativo, que tem por objetivo uma imersão na realidade, um conhecimento em profundidade para explicar os fatores que determinam os fenômenos (GIL, 2008). Para Prodanov e Freitas (2013, p. 53), na pesquisa explicativa, "o pesquisador procura explicar os porquês das coisas e suas causas, por meio do registro, da análise, da classificação e da interpretação dos fenômenos observados". Nesse sentido, além das entrevistas realizadas, os pesquisadores 
lançaram mão de notas, observações, registros fotográficos e da experiência de uma das pesquisadoras, que é consumidora dos produtos orgânicos da família. Dessa forma, a análise qualitativa foi orientada pela análise interpretativa, que segundo Gomes (2012), busca a lógica interna dos fatos, dos relatos e das observações e os situa no contexto dos atores.

\title{
3. CARACTERIZAÇÃo DA PROPRIEDADE DA FAMÍLIA DE AGRICULTORES ORGÂNICOS
}

O modelo de modernização da agricultura domina o ideário da produção agrícola e ainda atua na maior parte da produção de alimentos no mundo, o que chamamos de sistema de agricultura convencional. Entretanto, esse modelo de produção que consiste na exploração irrestrita do solo e dos recursos naturais para obter maior produtividade e rendimento econômico, não leva em conta na maioria das vezes, que a utilização constante de insumos externos e o manejo artificializado dos agroecossistemas podem implicar em problemas irreversíveis aos ecossistemas locais e a na saúde dos consumidores.

A agroecologia, segundo Balem e Silveira (2002) ocupa papel preponderante na construção do desenvolvimento sustentável, sendo parte integrante deste ao constituir-se num referencial na relação do homem com a natureza. De acordo com Gliessman (2000), a agroecologia é o estudo de processos econômicos e de agroecossistemas, como também, é um agente para as mudanças sociais e ecológicas complexas que necessitam ocorrer no futuro a fim de levar a agricultura para uma base verdadeiramente sustentável.

Neste sentido, a Agroecologia passa a ser a forma de produzir alimentos e de relacionar-se com o meio, sendo o agricultor, agente ativo da transformação e não mais passivo, como acontece no modelo da modernização da agricultura.

\begin{abstract}
O que se requer, então, é uma nova abordagem da agricultura e do desenvolvimento agrícola, que construa sobre aspectos de conservação de recursos da agricultura tradicional local, enquanto, ao mesmo tempo, se exploram conhecimentos e métodos ecológicos modernos. Essa abordagem é configurada na ciência da agroecologia que é definida como a aplicação de conceitos e princípios ecológicos no desenho e manejo de agroecossistemas sustentáveis. A agroecologia proporciona o conhecimento e a metodologia necessários para desenvolver uma agricultura que é ambientalmente consciente, altamente produtiva e economicamente viável. Ela abre a porta para o desenvolvimento de novos paradigmas da agricultura, em parte porque corta pela raiz a distinção entre a produção de conhecimento e sua aplicação. Valoriza o conhecimento local e empírico dos agricultores, a socialização desse conhecimento e sua aplicação ao objetivo comum da sustentabilidade. GLIESSMAN (2000, p.54).
\end{abstract}

A propriedade estudada possui 13 hectares, sendo estes, distribuídos em produção orgânica, área de benfeitorias de apoio a produção e moradia da família, área de reserva legal e preservação permanente, seguindo assim a legislação vigente (BRASIL, 2012), aderindo aos pressupostos de convivência produtiva de forma sustentável com os ecossistemas como sugere Gliessman (2000). Pelo estágio em que se encontra o manejo dos agroecossistemas da propriedade, é possível afirmar 
que a mesma se encontra em transição agroecológica. De acordo com Costabeber (1999, p. 107):

A transição agroecológica pode ser definida como o processo gradual de câmbio através do tempo, nas formas de manejo e gestão dos agroecossistemas, tendo como meta a passagem de um sistema de produção 'convencional' (...) a outro sistema de produção que incorpore princípios, métodos e tecnologias com base ecológica.

Trujillo (2003) salienta que o processo de reconversão da agricultura deve ser gradual, porque a transição de uma agricultura moderna e convencional para uma ecológica exige um processo lento do ponto de vista técnico. A propriedade encontrase em uma região privilegiada do ponto de vista ecossistêmico, ou seja, localizada no rebordo da serra. E como tem muitas áreas protegidas por mata nativa no entorno e não há lavouras convencionais próximas, o processo de reconversão está sendo mais rápido.

Na propriedade trabalham o casal em tempo integral, a filha e um dos filhos, de forma esporádica, visto que possuem outras ocupações. Como a demanda de trabalho é maior que a disponível atualmente é necessário à contratação de mão de obra externa na frequência de um ou dois dias por semana. A família é sócia da Cooperativa de Produção e Desenvolvimento Rural dos Agricultores Familiares de Santa Maria (COOPERCEDRO), que é uma cooperativa formada exclusivamente por agricultores familiares, sediada em Santa Maria. Um dos principais mercados da Coopercedro são os mercados institucionais. Em termos de mercado dos produtos produzidos pela família a cooperativa absorve em torno de $90 \%$ da produção e $10 \%$ desta, é destinada à comercialização das cestas entregues diretamente aos consumidores.

A família desenvolve sistemas de produção orgânicos desde 2001. Porém a propriedade era em outra área. Em 2011 a família mudou para uma área nova, esse fator trouxe uma série de transtornos, tais como a necessidade de implantação de novas áreas de pomares e de produção de hortaliças, assim como a construção de uma nova sede.

Outro fator limitante na propriedade é a deficiência de água para irrigação, segundo o agricultor esse é o principal problema relacionado à produção. Toda a água disponível vem de fontes internas na propriedade, açude e olho d'água, que no verão são insuficientes para a irrigação das plantações. Um fator positivo relacionado a origem da água é que essa não possui risco de contaminação, já que toda a propriedade é manejada com vistas à produção orgânica e as áreas de preservação permanentes são preservadas. Uma das formas utilizadas na propriedade para minimizar a deficiência de água para irrigação é o manejo do solo sempre priorizando a cobertura vegetal viva ou morta permanente. A cobertura do solo com palha, de preferência 0 ano todo, mantém as temperaturas baixas, evita perdas de água por evaporação e o estresse nas plantas (CALEGARI; CARLOS, 2014; CALEGARI, 2014). Os autores ressaltam que 85 a $90 \%$ da absorção de água e nutrientes nas culturas anuais ocorrem nos primeiros $20 \mathrm{~cm}$ do solo e a zona da raiz que está em um solo com temperaturas acima de $33^{\circ} \mathrm{C}$ perde a capacidade de absorver água e nutrientes. Esses aspectos apontados por Calegari e Carlos (2014) e Calegari (2014) demonstra a importância da cobertura de palha no solo, seja ela produzida e manejada no local ou introduzida como forma de mulching depois da implantação da cultura, como ocorre no plantio de hortaliças na propriedade estudada.

Sobre a importância da cobertura vegetal no solo o agricultor afirma: 


\begin{abstract}
"Nós não podemos deixar o solo sem cobertura nunca, precisamos manter a umidade com a cobertura porque falta água. Por isso, em tempos de maior demanda de mão de obra, quando precisamos abrir novas áreas de cultivo, nem sempre conseguimos fazer sem o uso do secante. Quando temos tempo, usamos aração e depois usamos cobertura morta com capim elefante ou outro capim produzido da propriedade, mas daí precisa preparar o solo, cortar o capim de outra área e colocar, dá um trabalho".
\end{abstract}

Em função da mudança de propriedade, da necessidade da abertura de novas áreas de plantio e devido à falta de mão de obra e necessidade de manejar as áreas com cobertura vegetal, em lugares que ainda se encontram em transição, ainda há uso de produto químico para dessecação. Importante salientar que esse uso é pontual e na maioria das vezes utilizado apenas na abertura de novas áreas de cultivo, ou seja, implantação de pomar e de áreas de horta.

Para promover à biodiversidade da propriedade a família utiliza diversas técnicas tais como: cultivos consorciados, rotação de culturas, recuperação e enriquecimento de APPs, manejo de mato e alternância de capinas, ausência de fogo, adubação verde, adubos orgânicos, diversificação da produção, sistemas agroflorestais (SAFs), quebra-ventos, cobertura do solo e cultivos em faixas. As práticas utilizadas no manejo da propriedade colaboram com o que Altieri (2002) afirma ser necessário para o manejo de sistemas agrícolas sustentáveis. Para Altieri, (2002) os agroecossistemas sustentáveis devem ser manejados de modo a manter a produtividade e a sustentabilidade ecológica no longo prazo, assim o manejo deve visar: manter a cobertura vegetal no solo para evitar erosão e perdas do sistema, como água e nutrientes; garantir o suprimento de matéria orgânica necessária para a vida no solo; promover mecanismos eficazes de reciclagem de nutrientes, tais como sistemas agroflorestais, uso de plantas recuperadoras, rotações de culturas, sistemas mistos de produção, consorciamento de plantas, integração de produção animal e produção vegetal; controle de pragas e doenças pelo equilíbrio do ecossistema.

Os SAFs podem ser definidos segundo Brasil (2012, art.2.) como:

\begin{abstract}
Sistemas de uso e ocupação do solo em que plantas lenhosas perenes são manejadas em associação com plantas herbáceas, arbustivas, arbóreas, culturas agrícolas, e forrageiras, em uma mesma unidade de manejo, de acordo com arranjo espacial e temporal, com diversidade de espécies nativas e interações entre estes componentes.
\end{abstract}

Segundo Steenbock e Vezzani (2013) os SAFs por imitar a dinâmica de sucessão ecológica de restauração natural de uma floresta nativa são mais equilibrados ecologicamente, mais resilientes e promovem uma maior ciclagem de nutrientes, além disso, visam potencializar os processos de acumulação de biomassa. Com isso têm-se sistemas altamente produtivos e altamente eficientes em funções ambientais.

A proteção física da floresta integrada à produção agrícola também é um fator a ser destacado nos SAFS, pois no caso do cultivo de bananas (Musa spp), na propriedade estudada, essa proteção garante que a cultura não sofra danos ocasionados pela geada e estresse fisiológico pelo frio no inverno. O município de Santa Maria não possui zoneamento agrícola para a cultura da banana, pois para essa cultura são necessárias temperaturas altas e uniformes, com mínimas não inferiores 
a $18^{\circ} \mathrm{C}$ e máximas não superiores a $34^{\circ} \mathrm{C}$. A faixa de temperatura ótima para o desenvolvimento das bananeiras comerciais é de 26 a $28^{\circ} \mathrm{C}$ e "temperaturas inferiores a $12^{\circ} \mathrm{C}$ provocam uma perturbação fisiológica nos frutos, conhecida como "chilling" ou friagem, que prejudica os tecidos, principalmente os da casca e do fruto" (MAPA, 2011, p. 01). O cultivo de banana em SAFs proporciona à família a comercialização de um fruto de clima tropical cultivado em uma região temperada com fortes incidências de geadas. Segundo a família eles conseguem colher os frutos para comercialização em oito meses no ano.

Pode-se observar que a propriedade é estruturada e aborda as questões de manejo de agroecossistemas necessárias para a produção orgânica. Os canteiros são distribuídos de forma intercalar de modo a garantir biodiversidade e interação entre às espécies, o que diminui a incidência de pragas e doenças. O uso de plantas como adubação verde é outra estratégia, como, por exemplo, na área de pomares de frutas cítricas, que além da preservação da vegetação espontânea é plantada soja perene (Neonotonia wightii) para conservação do solo, fixação de nitrogênio e proteção contra pragas. A adubação do solo é realizada com: cobertura morta, cobertura viva manejada com roçadas e cama de aviário, no entanto, em alguns momentos utilizam adubos químicos solúveis. A opção por adubos químicos solúveis se deve unicamente pela praticidade e facilidade no manejo, o que também está relacionado à questão da mão de obra.

O controle de pragas e doenças é realizado basicamente com manejo do agroecossistema, no entanto utilizam o bioinseticida Bacillus thuringiensis, onde a bactéria (Bacillus thuringiensis) age como patógeno em lagartas desfolhadoras, adoecendo-as e evitando que essas causem danos econômicos (ANGELO et al., 2010). A família afirma que têm perdido produção em função de ataques de pulgões, caracóis e traças. Pretendem implantar num futuro próximo o consorciamento das áreas de produção vegetal, principalmente de hortaliças com galinhas caipiras. Para Fukuoka (1995) apud Sales (2005) a associação entre galinhas, árvores frutíferas e cultivos de hortaliças trazem benefícios para os agricultores, pois as aves fazem o trabalho de arar, fertilizar o solo, controlar insetos e ervas daninhas.

O controle de plantas espontâneas é realizado com roçada, capina seletiva, cobertura morta e sombreamento nos sistemas agroflorestais, porém, em alguns locais utiliza-se a aração e controle químico para implantação de novas áreas, como já comentado anteriormente.

Outro fator observado é a busca por estratégias para ampliar o período de produção de determinadas culturas, como o caso do plantio de beterrabas (Beta vulgaris) e cenouras (Daucus carota), por exemplo. Para conseguir ter uma produção das mesmas o ano todo, fazem o plantio na primavera com cobertura verde sobre as mesmas, para que o sol e o calor do verão não as prejudiquem. Essas são culturas pouco adaptadas ao verão, principalmente a beterraba que é tipicamente de temperaturas amenas (TIVELLI et al, 2011). Assim, a família possui uma janela de colheita de beterraba e cenoura superior à maioria dos agricultores familiares que adotam o modelo produtivo convencional. Os SAFs implantados e em implantação, também devem ser considerados como uma estratégia importante de conservação da biodiversidade e de busca do equilíbrio ecológico da produção agrícola.

Percebe-se uma diversidade produtiva significativa na propriedade. Dentre os produtos comercializados estão: repolho (Brassica olerecea var. capitata), cenoura, beterraba, espinafre (Spinacia oleracea), alface (Lactuca sativa), couve flor (Brassica oleracea var. botrytis), brócolis (Brassica oleracea var. itálica), cebola (Allium cepa), tempero verde, tomate (Solanum lycopersicum), mandioca (Manihot esculenta); produção de frutas cítricas (Citrus sp) como laranja, bergamota e limão, banana, pêssego (Prunus pérsica) e figo (Ficus carica); batata doce (Ipomea batatas), além de 
várias espécies de cucurbitáceas como abóbora, morangas, melão, abobrinha, pepino. Os agricultores também produzem alguns alimentos para autoconsumo, como ovos, galinha caipira, leite, suínos, e outras frutas, inclusive frutas nativas, grãos como o feijão, milho, produtos processados artesanalmente como chimia, geléias e panificados. Com relação à diversidade produtiva a família afirmou que não planta mais produtos em função da carência de mão de obra, mas que tem uma série de alimentos que gostariam de cultivar. A família enxerga a entrega de cestas de produtos diretamente aos consumidores como uma alternativa importante e gostariam de ampliar esse mercado, pois o mesmo é mais rentável e atrativo.

A família considera os custos de produção baixos, visto que a maioria dos insumos é produzida na própria propriedade. O maior custo tem sido a aquisição de mudas de hortaliças. Como a propriedade não tem infraestrutura adequada para a produção de mudas e pela falta de mão de obra, há a necessidade da aquisição de praticamente toda a demanda, o que pode acarretar em outros problemas, para além do custo de produção, como: mudas produzidas de forma convencional, variedades poucas adaptadas às características ecossistêmicas do local de produção, mudas com problemas fitossanitários, questões que já vem sendo sentidas pelos agricultores.

Embora a produção orgânica seja o horizonte da família, pode-se observar que algumas dificuldades encontradas são resultantes do processo produtivo, as duas mais importantes são a falta de mão de obra e a de água para irrigação no verão. Essas duas questões são determinantes do uso de intervenções não agroecológicas na propriedade. Outro fator que desestruturou a produção foi à mudança de local da propriedade, pois a família teve que construir uma nova sede, com casa, galpões, estradas e açude, demandando grande parte da mão de obra que seria utilizada no manejo dos sistemas de produção. Afirmaram que agora, com a sede praticamente pronta, será possível realizar os próximos passos na propriedade.

\section{O MERCADO DE CIRCUITO CURTO DE PRODUTOS AGROECOLÓGICOS: A ENTREGA DE CESTAS DIRETAMENTE AOS CONSUMIDORES COMO ESTRATÉGIA}

Na maioria dos casos os produtores de alimentos orgânicos são constituintes da agricultura familiar, onde os mesmos sentem-se diminuídos no mercado competitivo em relação aos grandes produtores, que tomam o seu espaço desestimulando o desenvolvimento do pequeno agricultor. Isso ocorre devido ao crescimento econômico resultante da produção em grande escala, valorizando a produção das commodities em detrimento da produção de pequena escala e voltada ao abastecimento interno. Para os autores Niederle, Almeida e Vezzani (2013) a opção pela agricultura industrial tem padronizado a cadeia alimentar e homogeneizado algumas paisagens rurais, e isso tem afetado pequenos agricultores que não podem competir com grandes produtores e importações em grande escala.

É notável que a procura por alimentos orgânicos vem crescendo no país, já que atualmente existem alguns incentivos tanto governamentais quanto não governamentais para a implantação da agricultura orgânica. Segundo um relatório elaborado pelo Research Institute of Agriculture (FIBL) e pela Internetional Federation of Organic Agriculture Movements (IFOAM) chamado The World Organic Agriculture, - Brasil ocupa a $12^{a}$ posição dentre os países que dedicam parte de suas áreas agrícolas para a produção orgânica, destinando aproximadamente cerca de 705 mil hectares para o sistema de cultivo agroecológico (FIBL, INFOAM, 2016). O crescimento do consumo de produtos orgânicos está amparado por uma crescente tomada de consciência por parte dos consumidores dos problemas gerados pelo modelo de alimentação industrial. Pode-se afirmar que essa crescente consciência é 
despertada: 1- pelos debates de Segurança Alimentar e Nutricional (SAN); 2concepção de saúde ou dos problemas de saúde ocasionadas pela alimentação da atualidade; 3 - problemas ambientais e sociais do modelo de produção agrícola moderno.

Segundo Belik (2012, p. 96), a utilização do conceito moderno de SAN surgiu na "Conferência Internacional sobre Nutrição, realizada em 1992, sob o patrocínio da Organização das Nações Unidas (ONU) e que definiu um plano de ação direta para o combate à fome ao redor do mundo". Para o autor supracitado, nos documentos da conferência também se fez presente abordagens sobre a qualidade do alimento e das ligações entre nutrição e desenvolvimento agrícola. Nesse momento, surge, ainda, uma série de autores discutindo o rumo da alimentação mundial e seus efeitos no desenvolvimento social e cultural dos povos, culminando no surgimento de um campo do conhecimento sociológico que discute a alimentação e suas implicações, a Sociologia da Alimentação (MENELL et al., 1992).

Os problemas de saúde, ocasionados pela alimentação na atualidade, estão relacionados à contaminação por agrotóxicos e outros produtos químicos utilizados na formulação dos alimentos processados e ultraprocessados, o que tem sido relacionado a uma série de doenças (MORGAN, 2006; BIANCO et al., 2010); como a obesidade que cada vez mais cresce no mundo (OLIVEIRA, 2013; WHO, 2013); além disso, há a necessidade de apontar os chamados riscos alimentares, ou seja, alimentos industrializados contaminados e adulterados em massa (GUIVANT, 2002).

Aliadas à questão da saúde, aparecem as questões ambientais, culturais e sociais da alimentação. As questões ambientais se encontram nos efeitos visíveis do processo da Revolução Verde e tornam-se proposições imperativas para que haja mudanças nos sistemas de produção. Há também a necessidade de desconstruir as desconexões criadas pelo processo de modernização agrícola, em que os alimentos produzidos são descontextualizados, desterritorializados e desconectados dos processos de constituição histórica dos sistemas agrícolas (PETERSEN, 2013). Os sistemas de produção modernos produzem abundância de alimentos e, ao mesmo tempo, intensa degradação e contaminação no meio ambiente devido à atual lógica produtiva, além disso, há uma crescente diminuição da renda agrícola pelo aumento progressivo dos custos dos insumos e/ou aumento da subordinação econômica dos agricultores (WISKERKE, 2009).

Frente a essas problemáticas surge um movimento de contraposição ao atual modelo hegemônico de produção e alimentação. Esse padrão alternativo questiona o modelo alimentar industrial e propõe novas formas de organização de produção, mercado e consumo, o que denominamos de Narrativa Alternativa dos Alimentos (BALEM, 2015). O debate acerca das redes alternativas tornou-se uma característica cada vez mais acentuada em debates de desenvolvimento rural, desenvolvimento territorial e proposição de modelos alimentares diferenciados nos últimos 15 anos (MAYE, 2013). De acordo com Maye (2013) inúmeros estudos evidenciam a emergência de redes de produção e consumo mais aterradas e mais enraizadas em relações de reciprocidade, cultura alimentar, alimentação saudável, o que demonstra uma nova governança de sistemas agroalimentares. Os sistemas alimentares alternativos são baseados em espaços descentralizados, ecologicamente aterrados, e em consonância com as prerrogativas do desenvolvimento territorial e sustentável (McMICHEL, 2009; MORGAN, 2010). Desse modo, criam-se novas convenções de qualidade nas quais os elementos sociais, culturais, territoriais e de saúde compõem um sistema de qualidade, resgatando o conceito de segurança alimentar que havia sido abandonado nas três décadas finais do século $X X$ em consequência do imperativo da quantidade ofertada. 
Para Wiskerke (2009) a ligação do alimento com o contexto sociocultural e territorial é essencial para a construção de uma proposta de paradigma alimentar alternativo. Nesse sentido, os mercados de circuitos curtos são os canais estabelecidos para esse modelo alternativo. De acordo com Bava (2014):

\begin{abstract}
Por circuitos curtos entendemos a busca pela aproximação entre os locais de produção e consumo de bens e serviços; a redução da escala das distâncias percorridas pelos produtos a serem transportados; a diminuição da necessidade de uso de redes de transporte, energia e logística; a utilização de mão de obra do território; o financiamento em condições acessíveis aos micro e pequenos empreendedores com novos mecanismos de intermediação financeira; a maior participação dos atores sociais nos processos de decisão política, o maior cuidado com o meio ambiente do lugar em que vivem.
\end{abstract}

Para Darolt (2013, p. 142) "os mercados locais e a comercialização em circuitos curtos associados à agroecologia podem ser a chave para conectar produtores e consumidores de alimentos ecológicos e uma forma de impulsionar o desenvolvimento local". Darolt (2013) enumera as onze tipologias de mercados de circuito curto, dentre esses estão venda na propriedade, venda em cestas, feiras de produtores, pontos de venda coletiva, beira de estradas, entre outros. Percebemos que alguns tipos de mercado exigem maior participação e tempo dos consumidores do que outros. Garcia (2003) aponta que a necessidade de se readaptar às novas condições de vida que hoje o mundo vem vivenciando, seja, pela falta de tempo, pelo recurso financeiro escasso, ou, até mesmo pelo local disponível para a alimentação, as pessoas necessitam se adequar. Um dos fatores destacados pela autora, a falta de tempo das famílias e de uma pessoa com tempo livre destinada ao cuidado da compra e do preparo da alimentação levam os consumidores a buscar soluções mais rápidas e prontas, que na maioria dos casos estão nos produtos industrializados.

Os fatores tempo e praticidade discutidos por Garcia (2003) como determinantes de opções de consumo atual são importantes no mercado alternativo de entrega de cestas. Apesar da crescente oferta de alternativas alimentares, o consumidor ainda encontra dificuldade em localizar esses produtos, já que a "correria do mundo moderno" enxuga de maneira exaustiva os seus horários diariamente, impossibilitando os mesmos de realizar semanalmente suas compras nas feiras ou em varejos mais próximos que vendem produtos orgânicos. Observamos essa questão nessa pesquisa, pois praticamente todos os consumidores entrevistados ressaltaram essa questão. Além disso, o preço justo cobrado é outro fator que pesa bastante para os consumidores desse modelo de comercialização, pois a forma mais prática e acessível para a compra de alimentos orgânicos e de qualidade diferenciada seriam as gôndolas existentes em grandes mercados varejistas existentes em Santa Maria, no entanto para os consumidores que abordaram essa questão, os preços são muito elevados.

Outro fator que determinou a decisão dos consumidores em aderir à compra desses produtos, foi a preocupação com a saúde própria e dos comensais do grupo familiar, além do reconhecimento de estar adquirindo alimentos sem o uso de produtos químicos durante ou após a colheita. Para Niederle, Almeida e Vezzani (2013), graças ao contato direto com o produtor, o consumidor conhece os alimentos que está levando à mesa.

Foi também lembrada a segurança que os consumidores possuem ao saber que estão comprando diretamente do próprio produtor, o qual também realiza a entrega e que essa aproximação reflete em maior confiança, pois as dúvidas ou 
recomendações podem ser abordadas no momento da entrega. Como discutem os autores Godoy e Anjos (2007), o relacionamento entre produtor e consumidor, além da comercialização, também podem ser traduzidas na troca de experiências e saberes entre o rural e o urbano, em forma de receitas de preparo dos alimentos, informações nutricionais dos produtos e informações sobre as técnicas de produção agroecológicas. Neste sentido, podemos dizer que além da preocupação por ingerir alimentos mais saudáveis e a praticidade na aquisição dos produtos, os consumidores também zelam pela importância da relação direta entre produtor e consumidor, que acaba trazendo uma maior segurança aos mesmos na hora da compra.

No entanto, há consumidores que possuem uma abordagem mais crítica em relação a esse mercado "mais cômodo e prático". Um dos entrevistados chamou atenção ao abordar a importância das feiras ao invés da entrega domiciliar, para evitar o comodismo nas grandes cidades. Ele argumenta: "havendo uma feira você se dispõe a sair um pouco de casa, deixar aquele comodismo de receber as cestinhas prontas, eu acho que isso é uma forma de comodismo, uma forma de acomodar o consumidor". A feira, por sua característica é um espaço de socialização de trocas mais intensas e significativas, onde os consumidores se relacionam com vários agricultores. Na entrega de cestas, as possibilidades de troca para os consumidores são bem menores.

\subsection{A CONSTRUCCÃO DO PROCESSO DE ENTREGA DOMICILIAR DE CESTAS DE PRODUTOS AGROECOLÓGICOS}

Para a entrega das cestas montadas pela família, o produtor recebeu o apoio da Empresa de Assistência Técnica e Extensão Rural da cidade de Santa Maria (EMATER). Anteriormente a família realizava feiras e também entregava produtos juntamente a outros produtores para empresas relacionadas a programas do governo como o Plano Nacional de Alimentação Escolar (PNAE). A família passou por processos de remodelações, devido à troca de área produtiva e com a assistência técnica surgiu a ideia de realizar a entrega dos alimentos através de cestas em pontos estratégicos, facilitando o agricultor por serem pontos próximos da propriedade e próximos de seus clientes.

As indicações dos produtos da família inicialmente foram feitas pelos assistentes da EMATER envolvidos, e posteriormente foi passado de amigos para conhecidos e também com frequência em ambientes de trabalho. A ideia inicial era de que fosse estipulado um valor para as cestas que seriam entregues semanalmente $e$ dentro desse valor, o agricultor as organizaria com os produtos disponíveis no momento. O consumidor passaria a receber as "cestas fechadas" de acordo com o que fosse produzido na propriedade, justamente pela dificuldade do produtor em produzir algumas culturas em determinadas épocas e por questões de sazonalidade de produção. Porém, alguns dos consumidores não aderiram à ideia e optaram pela escolha dos produtos, desse modo, é entregue uma lista do que é cultivado na propriedade e a partir dela são feitas as escolhas. Mais da metade dos consumidores optam pela seleção de produtos, enquanto os outros preferem comprar o que tem disponível na propriedade semanalmente, optando pela "cesta fechada", assim combinam um valor semanal com o agricultor e esse organiza a cesta livremente.

A família afirma que se as cestas fossem "fechadas" demandaria menos mão de obra e facilitaria o gerenciamento dos sistemas de produção e comercialização. Sobre a entrega de cestas fechadas, sem a opção de escolha dos produtos semanalmente, os consumidores que optam por essa modalidade ressaltam a possibilidade de variar a alimentação, respeitar os processos produtivos da propriedade e afirmam que o elemento surpresa os obriga a comer alimentos variados. 
Como afirma uma consumidora: "Porque a gente tem uma alimentação bem variada, pra mim não importa muito que tipo de produto, desde que ele seja variado, que ele seja novo, que ele seja fresco". Uma das consumidoras afirma que prefere comprar a cesta sem saber o que vai ter nela, pois assim, se obriga a comer uma variedade maior de alimentos. Afirma: "Hoje nós comemos espinafre, couve folha, batata doce, que eram alimentos que raramente comíamos. Se eu fosse escolher, nunca escolheria espinafre, por exemplo. Agora a gente sabe fazer espinafre de várias formas." A escolha, segundo a consumidora estreita o consumo, pois as pessoas tendem a pedir sempre os mesmos produtos e prejudica o trabalho dos agricultores e reduz a variedade de produtos consumidos pelas famílias. É necessário considerar que a propriedade não é um mercado convencional que tem sempre disponíveis determinados produtos, na verdade os consumidores preferem escolher porque não conseguem se desligar dessa lógica do grande mercado. Outra questão a ser considerada é a sazonalidade dos produtos e os eventos climáticos, nem sempre vai ser possível o agricultor ter disponível todos os produtos da preferência dos consumidores, mas com certeza terá um substituto.

Outro aspecto que a família abordou é que eles enxergam a entrega via cestas como um mercado potencial e emergente, no entanto necessitam de assessoria para organizar o grupo de consumidores e a rota de entregas, pois seria inviável entregar em todas as residências se aumentasse o número de consumidores. Hoje eles entregam em três pontos estratégicos e os consumidores envolvidos em cada ponto se organizam para distribuição. Para os agricultores o ideal é entregar em pontos de referência, onde um ponto atingiria um grupo pequeno de consumidores. Assim facilitaria a entrega e estaria próximo a todos os consumidores. Outra questão importante dos pontos de referência é que não aumentaria o valor dos produtos para os consumidores, pela facilidade de logística.

Uma das maiores vantagens dessa entrega domiciliar é o contato direto com o produtor, relação a qual foi enfatizada por todos os entrevistados. O sentimento de admiração e confiança demonstrado pelos consumidores foi visível em todas as entrevistas. O excerto a seguir demonstra isso: "o trabalho deles é uma luta, é remar contra a maré, eles desafiam um processo diferenciado e que a gente percebe como são corajosos e que perseguem aquilo que querem".

Os consumidores têm consciência da qualidade diferenciada dos produtos, além disso, acreditam estar fortalecendo a agricultura familiar, como afirma um consumidor, que diz que a motivação pelo consumo dos produtos da família foi: " $A$ busca por alimento sem contaminação por agrotóxicos e para valorizar a agricultura familiar e os agricultores que fazem dela uma agricultura diferente". Uma consumidora afirma que a entrega via cestas: "facilita a aquisição porque antes eu ia à feira fazer essa compra, então a partir da segurança que o produto é entregue no meu local de trabalho me facilita um monte né. E eu acho isso bem importante, até porque a gente conhece as pessoas que produzem".

Outros consumidores afirmaram que consomem os produtos por confiança e também movidos por um sentimento de nostalgia, pois são de origem rural. Para esses consumidores os produtos entregues nas cestas e a relação construída com a família lembram essa origem. Além disso, buscam alimentação mais saudável e agroecológica, por necessitarem de alimentos de melhor qualidade em função de problemas de saúde.

Percebe-se que todos os consumidores optam pelo consumo de alimentos orgânicos e da agricultura familiar em primeiro lugar por uma questão de saúde, em segundo lugar por uma questão de valorização dos agricultores e em terceiro lugar por buscar reconexão com suas origens. A questão ambiental e de preservação, foi fracamente abordada pelos consumidores. 
Um dos maiores problemas enfrentados na construção desse mercado é a seletividade dos produtos por parte dos consumidores, pois a família não dispõe de um canal de comunicação eficiente para informar os consumidores a lista de produtos disponíveis semanalmente. O constato se dá via telefone celular e tem sido insuficiente e ineficaz. Por outro lado, o agricultor tem dificuldade de organizar as cestas quando ocorre uma seletividade maior de produtos por parte dos consumidores, pois isso exige mais planejamento e mais interação entre ambas as partes. Para a família, o sistema ideal de comercialização via cestas seria o de "cestas fechadas", montadas dentro de um valor previamente estipulado e com os produtos disponíveis no momento, isso sanaria uma das principais dificuldades enfrentadas que é a comunicação e a prévia escolha dos produtos pelos consumidores. Essa questão sugere que esses mercados de proximidade exigem tecnologias modernas para auxiliá-los. Um aplicativo de celular ou de um site com a divulgação dos produtos da família resolveria em parte essa dificuldade de comunicação, no entanto demandaria mais especialização e domínio de tecnologias de comunicação por parte da família. Nessa questão cabe alguns questionamentos e talvez agendas de pesquisa: o modelo ideal não seria o proposto pela família, as "cestas fechadas", pois estaria mais de acordo com os processos naturais e com as características da agricultura familiar? Nesse caso, deveria haver ampliação dos espaços de diálogo entre consumidores e agricultores. Ou precisamos avançar com pesquisas e desenvolvimentos de suportes adequados para os mercados de circuito curtos, tais como ferramentas de Tecnologias de Informação e Comunicação (TICs) e maior assessoria aos agricultores no processo de construção dos diferentes mercados de circuito curto? O uso de tecnologias de comunicação pode ser um fator fundamental para melhorar a conexão entre agricultor e consumidor, tal ideia que também foi salientada por vários consumidores entrevistados, onde foi relatado que através de um aplicativo ou site o produtor poderia disponibilizar os produtos para a venda semanalmente, avisar datas e horários para realizar as encomendas e entregas, facilitando ainda mais este mercado utilizando esses recursos.

\subsection{A CERTIFICAÇÃO DOS PRODUTOS AGROECOLÓGICOS: UMA NECESSIDADE SENTIDA?}

O crescimento de incentivos governamentais a respeito da produção e consumo sustentável na agricultura é visto em quase todos os países do mundo, e isso decorre das metas articuladas com a Organização das Nações Unidas (ONU) para serem alcançadas até o ano de 2030. Dentro dos 17 acordos apresentados em ordem pela organização, está a busca pela agricultura sustentável ligada ao fim da fome, a qual ocupa o segundo lugar da lista depois da erradicação da pobreza (AGENDA 2030 - ONU, 2015).

Nota-se que os sistemas agroecológicos de produção são os melhores para a questão da agricultura sustentável, pois além de levar em conta a preservação e o uso consciente dos recursos naturais, proporciona também a população uma alimentação mais saudável. Essas questões chamam a atenção dos consumidores já que atualmente estão mais preocupados com a saúde e o bem-estar, dando origem a um novo tipo de consumidor. Os consumidores "verdes" ou ecologicamente conscientes e responsáveis são definidos ou representados, por aqueles indivíduos que buscam para consumo apenas os produtos que não exerçam nenhum prejuízo ao meio ambiente (GRAZIANO et.al, 2006).

Para garantir a esses consumidores a veracidade de que estão adquirindo produtos sustentáveis, temos o processo de certificação dos alimentos realizado por instituições privadas ou públicas. As certificações ecológicas e orgânicas surgem nos 
diferentes países de modo a controlar e servir como instrumento de verificação de conformidades ambientais e estão ligadas ao aparecimento da sustentabilidade como preocupação global (NIEDERLE et al., 2013).

Quando questionamos os consumidores a respeito da necessidade de certificação dos produtos da família, os entrevistados responderam que o mais importante é a relação de confiança entre o produtor e o consumidor. Pelo fato de existir um forte elo de confiança para muitos consumidores o processo de certificação não interfere e é dispensável. No entanto os consumidores afirmam que se houver a expansão da venda dos produtos através das cestas, talvez a certificação seria fundamental, principalmente para aqueles que não conhecem a família.

É válido ressaltar que esse sentimento de confiança é proporcionado pelo mercado de circuito curto de entrega domiciliar, onde há o contato presencial entre o produtor e o consumidor gerando diálogos a respeito da produção dos alimentos. Em uma das entrevistas, o entrevistado ressalta a importância desse contato, ele ainda dá ênfase quando diz "além da entrega da cesta, há estabelecido um grau de confiança e amizade com o agricultor que traz os alimentos que irão alimentar minha família". Outro afirma: "a gente conversa, pergunta quando tem dúvida, eu gosto de esperar a entrega da cesta, pois assim consigo conversar com o agricultor".

Está claro que essa relação estabelecida entre os consumidores e a família, se deu por conta de um processo construído, onde inclusive, alguns consumidores foram conhecer a propriedade e se certificaram dos alimentos que estavam recebendo em casa. Um consumidor disse que não conhece a propriedade, mas que quer conhecer logo, pois já são amigos da família e que tem muita curiosidade de saber onde esses moram e cultivam os alimentos. Outro fator fundamental na relação construída foi à indicação do agricultor por parte de consumidores que já conhecem a propriedade, o que reforça a confiança. Ou seja, o contato próximo, dialogado e reflexivo que os mercados de circuito curto conseguem estabelecer.

Os consumidores percebem que os produtos são diferenciados ao relatar que os alimentos possuem um sabor diferente do convencional, como relatado em uma entrevista: "depois que comecei a comprar a cesta da família, voltei a comer beterraba com gosto de beterraba". Ela reforçou, assim como a maioria dos consumidores, que o alimento tem outro paladar, que ao "pegar um produto da cesta vê pela aparência que tem outro jeito, o cheiro, o gosto, tudo é diferente dos alimentos consumidos de grandes mercados".

\subsection{A DIFICULDADE DE ASSISTÊNCIA TÉCNICA ESPECIALIZADA AOS AGRICULTORES ORGÂNICOS}

Como a construção de uma Narrativa Alternativa dos Alimentos passa necessariamente pelo redesenho dos sistemas de produção, é necessário um perfil profissional diferenciado para dar assessoria aos modelos de agriculturas sustentáveis. É notável a falta de profissionais com experiência na área de produção orgânica e agroecológica.

Segundo o extensionista do escritório municipal da EMATER-RS de Santa Maria, muitos agricultores não conseguem produzir de forma orgânica por falta de técnicos especializados nessa área para dar assessoria. Para ele: "Não tem assistência técnica, não existe. 99\% dos agentes de desenvolvimento e assistência técnica hoje são formados para vender venenos e insumos, assim os agricultores dependem muito deles (mesmos) para se organizar por conta própria". Para Carvalho (2014) a precariedade da assistência técnica recebida pelos produtores, as dificuldades de acesso a financiamento e a pouca divulgação das qualidades da 
produção orgânica completam o quadro de gargalos econômicos traçado pelos produtores.

Assim, como a dificuldade de produzir é maior e qualquer manejo errado do produtor sem orientação, acarreta em custos mais elevados, é perceptível a necessidade de uma orientação especializada para poder produzir da melhor forma e mais rentável possível. Portanto, a capacitação e apoio técnico à produção são fatores essenciais à diminuição dos custos de produção e melhoria da qualidade dos produtos (CARVALHO, 2014). Balem (2015), identificou que um dos maiores problemas para os agricultores que optam pela produção orgânica ou mais sustentável tem sido a assistência técnica, que quando existe está completamente em desacordo com as premissas de produção agroecológica. Barbosa e Sousa (2012) também ressaltam que uma das principais dificuldades enfrentadas pelos produtores nesse mercado é o acesso limitado à assistência técnica. Nesta questão abordada pelos autores fica clara a falta de especializações que se tem na área.

Segundo Sassi (2011) atualmente muitos agricultores não dispõem de assistência técnica e até que estes serviços aconteçam o agricultor não poderia ficar esperando. Uma das formas que os agricultores utilizam para sanar o problema da falta de assessoria é a formação de grupos, muitas vezes para formação de uma cooperativa descentralizada, administradas por eles mesmos (SASSI, 2011). Com esse modelo de organização os agricultores tendem a se responsabilizar pela produção e venda de seus produtos, gerando assim vantagens para os mesmos. No entanto, mesmo com a organização, os agricultores necessitam de assessoria técnica, pois como afirma Sumberg e Sabates-Wheeler (2011), esses precisam desenvolver novas habilidades, pois as estratégias e estruturas de relocalização da agricultura exigem conhecimentos que não dominam ou perderam com o processo de modernização. Em estudo realizado por Balem (2015) percebe-se que a agroecologia é mais complexa e mais difícil para os agricultores, o que exige conhecimentos que eles não dominam.

O trabalho de extensão rural, no caso da família deste ensaio, esteve muito mais relacionado à organização dos consumidores e hoje tem uma ação voltada ao gerenciamento da propriedade. A ação mais voltada à produção e manejo de agroecossistemas é realizada pelo filho, que é Engenheiro Agrônomo. Mas como o extensionista entrevistado ressalta, essa é uma situação de exceção e não regra. Para ele existem inúmeros agricultores que poderiam fazer a reconversão dos sistemas de produção e ingressar em mercados de circuitos curtos, melhorando a renda, a qualidade de vida e construindo novas opções de alimentação para os consumidores urbanos, a exemplos das experiências já existentes em Santa Maria. Mas, essas não se ampliam por falta de assessoria adequada.

Segundo o extensionista entrevistado seria necessária uma equipe de técnicos maior e mais qualificada para atender agricultores e atuar na construção dos mercados de circuito curto agroecológicos. Para o extensionista, a família estudada nesse artigo já superou muitos gargalos técnicos e produtivos, porém a organização do processo de comercialização via cestas ainda precisa ser melhorada, pois há bastante dificuldade de comunicação entre os consumidores e a família. E para aqueles consumidores que preferem escolher os produtos semanalmente, essa dificuldade de diálogo é um problema.

Essas questões levantadas pela extensão rural demonstram que a construção de uma Narrativa Alternativa dos Alimentos perpassa por várias áreas, não somente pela assistência técnica produtiva, como aponta Balem (2015). A produção agroecológica e a comercialização dessa, em mercados de circuito curto, exigem uma série de aprendizados e desenvolvimento de ações que dialogam com uma sociedade moderna e com modos de consumo já impactado. Dessa forma, o aprendizado não é 
somente para os produtores, mas também para os consumidores. Uma das sugestões de consumidores durante a pesquisa foi organizar visitas dos consumidores à propriedade. Esse, talvez seja um dos caminhos para ampliar esse processo de aprendizagem, aumentar ainda mais o contato entre produtor e consumidor e, além disso, garantir a confiança. Essas visitas, poderiam ser organizadas em grupos, assim os consumidores poderiam conhecer a propriedade, a forma de cultivo dos produtos antes de chegar até a mesa de suas casas, promovendo uma oportuna interação.

\section{CONSIDERAÇÕES FINAIS}

A certificação, para o grupo de consumidores atual não representa algo necessário, mas pode ser levado em consideração assim que o agricultor estiver terminado o processo de transição e ter sua produção inteiramente agroecológica, pois poderá expandir as suas vendas e acessar outros mercados.

Percebemos que a entrega de produtos orgânicos em cestas pode ser avaliado através de algumas questões centrais: 1 - atinge um grupo de consumidores conscientes e que buscam alimentos de maior qualidade, mas preferem a comodidade de receber em casa os produtos; 2- a relação entre agricultor e consumidores é baseada na confiança e na troca de saberes; 3 - os consumidores tendem a preferir a escolha de produtos para compor a cestas e não a compra às cegas, ou seja, sem saber o que tem na cesta; 4- seria importante os consumidores acessarem espaços de diálogo sobre alimentação, produção orgânica e agricultura familiar, pois se percebe que muitos têm dificuldade de compreender a dinâmica da propriedade e da família, e tendem a querer um atendimento parecido com o encontrado em mercados, principalmente no que tange aos tipos de produtos.

Concluímos que o processo de venda a partir do mercado de circuito curto com entrega de cestas beneficia tanto a família produtora quanto os consumidores. Os consumidores que possuíam dificuldades de acessar produtos de qualidade diferenciada, hoje podem receber seus alimentos em casa.

Contudo, ainda há espaço de aprendizado nessa relação de produção e consumo, pois a experiência mostra que há desafios a serem superados, tais como: organização do mercado de circuito curto, já que a comunicação entre a família agricultora e os consumidores por vezes é difícil; assistência técnica que apesar de existente é insuficiente para atender uma demanda maior de agricultores; e aprendizados necessários tanto para os agricultores quanto para os consumidores. Nesse último, percebe-se que os consumidores têm dificuldade de perceber e conhecer a sazonalidade dos cultivos agropecuários, os eventos climáticos que por vezes comprometem a produção e a limitação de oferta de determinados produtos em algumas épocas. Por outro lado, a família agricultora tem dificuldade de organizar as cestas quando ocorre uma seletividade maior de produtos por parte dos consumidores. Para a família, o sistema ideal de comercialização via cestas seriam as cestas fechadas, organizadas dentro de um valor previamente estipulado e com os produtos disponíveis no momento, pois uma das principais dificuldades enfrentadas é a comunicação e a previa escolha dos produtos pelos consumidores, o que ressalta a importância de um aplicativo a ser acessado por um dispositivo móvel ou site para facilitar esse processo.

\section{REFERÊNCIAS}

ALTIERI, M. A. Agroecologia: bases científicas para uma agricultura sustentável. Guaíba: Agropecuária, 2002. 
ANGELO, E. A.; VILAS-BÔAS, G. T.; CASTRO-GÓMEZ, R. J. H. Bacillus thuringiensis: características gerais e fermentação. Semina: Ciências Agrárias, Londrina, v. 31, n. 4, p. 945-958, out./dez. 2010

BALEM, T. A. O programa de alimentação escolar brasileiro e a narrativa alternativa dos alimentos: convergências e desafios. 2015. 275f. Dissertação (Mestrado em Extensão Rural) - Programa de Pós-Graduação em Extensão Rural, Universidade Federal de Santa Maria.

BALEM, T. A.; SILVEIRA, P. R. Agroecologia: além de uma ciência, um modo de vida e uma política pública. In: Simpósio IESA/Sociedade Brasileira de Sistemas de Produção, 5., 2002, Florianópolis-SC. Anais... Florianópolis: IESA/Sociedade Brasileira de Sistemas de Produção, 2002, CD-ROM.

BARBOSA, W. de F.; SOUSA, E. P. Agricultura orgânica no Brasil: características e desafios. Revista Economia \& Tecnologia (RET), v. 8, n. 4, p. 6774, out./dez, 2012.

BAVA, S. C. Circuitos Curtos de Produção e Consumo. In: BARTELT, D. D. (Org.). Um campeão visto de perto: uma análise do modelo de Desenvolvimento Brasileiro. Rio de Janeiro: Heinrich-Böll-Stiftung, 2012. (Série Democracia). p. 178-187. Disponível em: https://br.boell.org/sites/default/files/democracia_inside_a_ champion_port_final.pdf. Acesso em: 12 mar. 2017.

BELIK, W. A Política Brasileira de Segurança Alimentar e Nutricional: concepção e resultados. Segurança alimentar e nutricional, Campinas, n.19, v.2, p. 94-110, 2012.

BIANCHINI, V.; MEDAETS, J. P. P. Da revolução verde a agroecologia: Plano Brasil Agroecológico. 2013. Disponível em: http://migre.me/wiPLY. Acesso em: 12 mar. 2017.

BIANCO, A. L.; CASSIANO, L. de., RIBEIRO, A. C. Superalimentados, mas subnutridos - um diagnóstico do sistema alimentar industrial. Ambiente \& Sociedade, v. 12 , n. 1, p. 203-206, 2009.

BRASIL. Lei n. 12.651, de 25 de maio de 2012. Dispõe sobre a proteção da vegetação nativa; altera as Leis (...). Diário Oficial da União, Poder Executivo, Brasília, DF, 25 de maio de 2012

CALEGARI, A. Perspectivas e estratégias para a sustentabilidade e o aumento da biodiversidade dos sistemas agrícolas com o uso de adubos verdes. In: LIMA FILHO, O. F. de et al. (Eds.). Adubação verde e plantas de cobertura no Brasil: fundamentos e prática. Brasília, DF: Embrapa, 2014. v. 1 p. 19-36.

CALEGARI, A.; CARLOS, J. A. D. Recomendações de plantio e informações gerais obre o uso de espécies para adubação verde no Brasil. In: LIMA FILHO, O. F. de et al. (Eds.). Adubação verde e plantas de cobertura no Brasil: fundamentos e prática. Brasília, DF: Embrapa, 2014. v. 2 p. 451-478.

CARVALHO, R. Desafios para a produção orgânica do ERJ. Cadernos do Desenvolvimento Fluminense, Rio de Janeiro, n. 4, p. 23-41, 2014. 
COSTABEBER, J. Transição agroecológica: do produtivíssimo à ecologização. In: BRACAGIOLI NETO, A. (Org.). Sustentabilidade e cidadania: O papel da extensão rural. Porto Alegre: EMATER/RS, pp. 67-117, 1999.

DAROLT, M. R. Circuitos curtos de comercialização de alimentos ecológicos. In: NIEDERLE, P.A.; ALMEIDA, L.; VEZZANI, F.M. (Org.). Agroecologia: práticas, mercados e políticas para uma nova agricultura. Curitiba: Kayrós, 2013. p. 139-170.

FIBL/IFOAM. Research Institute of Organic Agriculture/International Federation of Organic Agriculture Movements. The world of organic agriculture: statistics and emerging trends, 2016.

FRIEDMANN, H. After Midas's Feast: alternative food regimes for the future. In: ALLEN, P. (ed.) Food for the future: conditions and contradictions of sustainability. California: John Wiley e Sons, Inc., 1993. p. 213-233.

GARCIA, R. W. D. Reflexos da globalização na cultura alimentar: considerações sobre as mudanças na alimentação urbana. Revista Nutrição, Campinas, n. 16, v. 4, p. 483492, 2003.

GIL, A. C. Como elaborar projetos de pesquisa. -4. ed.- São Paulo: Atlas, 2008.

GLIESSMAN, S. R. Agroecologia: processos Ecológicos em Agricultura sustentável. Porto alegre: editora Universidade/UFRGS, 2000.

GODOY, W. I.; ANJOS, F. S. dos. A importância das feiras livres ecológicas: um espaço de trocas e saberes da economia local. Revista Brasileira de Agroecologia v.2, n.1, fev, 2007.

GOMES, R. Análise e interpretação de dados de pesquisa qualitativa. In: DESLANDES, S. F.; GOMES, R. MINAYO, M. C. de S. (org.). Pesquisa social: teoria, método e criatividade. - 31. Ed- Petrópolis, RJ: Vozes. p. 79-108, 2012.

GOODMANN, D. The "Turn Quality" and alternative food pratices: reflections and agenda. Journal of Rural Studies, v.19, n.1, 2003.

GRAZIANO, G. O.; et al. A certificação de produtos orgânicos no Brasil: um estudo exploratório. In: Congresso da Sociedade Brasileira de Economia e Sociologia Rural, 44. 2006, Fortaleza. Anais... Brasília: SOBER, 2006.

GUELBER SALES, M. N. Criação de galinhas em sistemas agroecológicos. Vitória, ES: Incaper, 2005. Disponível em: encurtador.com.br/jolVX. Acesso em :22 jan. 2019.

GUIVANT, J. S. Riscos alimentares: novos desafios para a sociologia ambiental e a teoria social. Desenvolvimento e Meio Ambiente. n. 5. p. 89-99. jan./jun, 2002.

INSTITUTO BRASILEIRO DE GEOGRAFIA E ESTATÍSTICA (IBGE). Brasil. Rio Grande do Sul. Santa Maria. IBGE, 2019. Disponível em: https://cidades.ibge.gov.br/brasil/rs/santa-maria/panorama. Acesso em: 12 jan. 2019. 
MAYE, D. Moving alternative food networks beyond the niche. International Journal of Sociology, Agriculture and Food, v. 20, n. 3, 2013, p. 383-389, 2013.

McMICHAEL, P. A. food regime genealogy. Journal of Peasant Studies, v.36, n.1, p.139-169, 2009.

MENELL, S. MURCOTT, A.; OTTERLOO, A. H. VAN. The sociology of food: eating, diet and culture. London: Sage Publications, 1992.

MINISTÉRIO DA AGRICULTURA, PECUÁRIA E ABASTECIMENTO (MAPA). Portaria n. 95, de 7 de abril de 2011. Divulga o Zoneamento Agrícola para a cultura de banana no Estado do Rio Grande do Sul. Disponível em: http://sistemasweb.agricultura.gov.br/sislegis/action/detalhaAto.do?method=visualiza rAtoPortalMapa\&chave=978888252. Acesso em: 24 jan. 2019.

MORGAN, K. J. Local and green, global and fair: the ethical foodscape and the politics of care. Environmentand planning A, v. 42, n. 8, p.1852 - 1867, 2010.

MORGAN, K. School food and the public domain: the politics of the public plate. The Political Quarterly, v. 77, n. 3, 2006.

MORGAN, K.; SONNINO, R. (b). Rethinking school food: the power of the public plate. IN: STATE OF THE WORLD. Transforming cultures: from consumerism to sustainability. New York: London: 2010. p.69-74, 2010.

NIEDERLE, P.; ALMEIDA, L.; VEZZANI, F. M. Introdução. In: NIEDERLE, P.; ALMEIDA, L. de; VEZZANI, F. M. (Orgs). Agroecologia: práticas, mercados e políticas para uma nova agricultura. Curitiba: Cairós, 2013. p. 13 - 22.

OLIVEIRA, M. L. Estimativa dos custos da obesidade para o sistema único de saúde do Brasil. Brasília, 109 f. Tese (doutorado) - Faculdade de Ciências da Saúde, Universidade de Brasília, 2013.

ORGANIZAÇÃO DAS NAÇÕES UNIDAS (ONU). Agenda 2030. Edição de 11 de fevereiro de 2016. Disponível em: http://www.br.undp.org/content/dam/brazil/docs/agenda2030/undpbr-Agenda2030completo-pt-br-2016.pdf . Acesso em: 12 mar. 2017.

PETERSEN, P. Agroecologia e a superação do paradigma da modernização. In: NIEDERLE, P.; ALMEIDA, L. de; VEZZANI, F. M. (Orgs). Agroecologia: práticas, mercados e políticas para uma nova agricultura. Curitiba: Cairós, 2013. p. 69-104.

PRODANOV, C. C.; FREITAS, E. C. Metodologia do trabalho científico: métodos e técnicas da pesquisa e do trabalho acadêmico. Novo Hamburgo: Universidade FEEVALE. 2013.

SASSI, C. R. Proposta de política de assistência técnica agrícola: um desafio a técnicos e agricultores. Publ. UEPG Ci. Exatas Terra, Ciências Agrárias e Engenharias, Ponta Grossa, n. 17, v. 2, p. 119-129, jul./dez. 2011.

STEENBOCK, W.; VEZZANI, F. M. Agrofloresta: aprendendo a produzir com a natureza. Curitiba, 2013.148p. 
SUMBERG, J. SABATES-WHEELER, R. Linking agricultural development to school feeding in sub-Saharan Africa: theoretical perspectives. Food Policy, v. 36, p. 341349. 2011.

TIVELLI, S. W. et al. Beterraba: do plantio à comercialização. Campinas: Instituto Agronômico, 2011. 45p. (Série Tecnologia APTA. Boletim Técnico IAC, 210)

TRUJILLO, F. S. de P. Medioambiente y Agricultura: ¿La Nueva 'Cuestión Agraria' del Siglo XXI? (em prensa). España, Córdoba: Departamento de CienciasSociales y Humanidades: Instituto de Sociología y Estudios Campesinos de laUniversidad de Córdoba, 2004. 17 p.

WISKERKE, J.S.C. On places lost and places regained: reflections on the alternative food geography and sustainable regional development. International Planning Studies, v. 14, n. 4, p. $369-387,2009$.

WORLD HEALTH ORGANIZATION (WHO). Obesity and overweight. 2013. (Fact sheet n., 311, Updated March 2013). Disponível em: http://www.who.int/mediacentre/factsheets/ fs311/en/. Acesso em: 02 set. 2013. 